


\section{About IJMA [last updated October, $\left.1^{\text {st }}, 2021\right]$}

$\checkmark$ International Journal of Medical Arts is the Official Journal of the Damietta Faculty of Medicine, AlAzhar University, Egypt

$\checkmark$ It is an International, Open Access, Double-blind, Peer-reviewed Journal

$\checkmark$ Published four times a year

$\checkmark$ The First Issue was published in July 2019

$\checkmark$ Published under the following license: Creative Commons Attribution-ShareAlike 4.0 International Public License (CC BY-SA 4.0). It had updated from the Creative Commons license [CC BY] in volume 2, Issue 4, October 2020 About IJMA

$\checkmark$ The Egyptian Knowledge Bank hosts the web site of IJMA

$\checkmark$ The Egyptian Knowledge Bank supports IJMA

$\checkmark$ IJMA follows the regulations of the International Committee of Medical Journal Editors

$\checkmark$ IJMA is indexed in the "Directory of Open Access Journals" [15 January 2021].

$\checkmark$ IJMA is indexed in J-Gate [29-6-2021]

$\checkmark$ IJMA is a member of the International Society of Managing and Technical Editors

$\checkmark$ Listed in "Index Copernicus", "Publons", "Academic resource index [ResearchBib]" "Electronics journal library", "Eurasian Scientific Journal Index", "WorldCat" Superstar Journal Database, and "Citefactor"

$\checkmark$ IJMA introduced to the search engine [BASE] through DOAJ

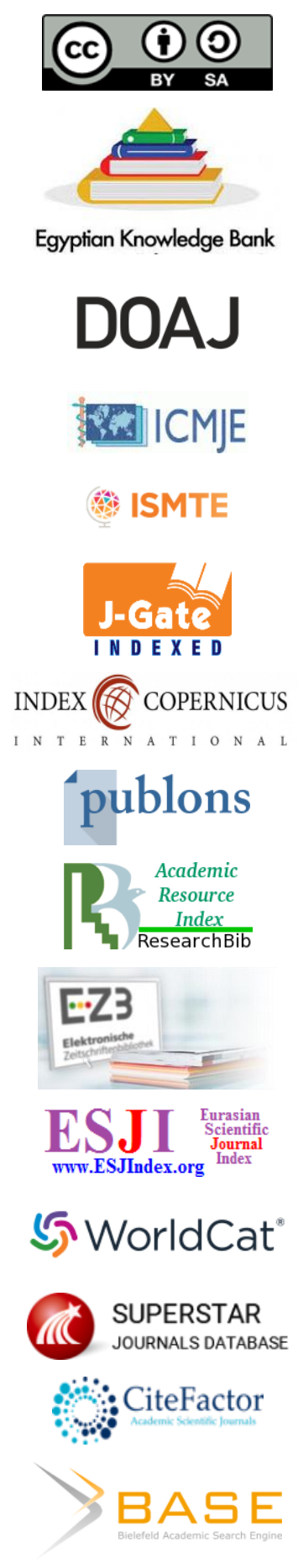




Available online at Journal Website
https://ijma.journals.ekb.eg/
Main subject [Cardiothoracic Surgery] ${ }^{*}$

Original Article

\title{
Retrospective Study of Redo Mitral Valve Surgery in Cardiothoracic Surgery Department Al-Hussein University Hospital
}

\author{
El-Sayed Ramadan Mohamed Hassan [1], Ibrahim Mahmoud Elsayaad [2], Mohamed El-Desouky Sharaa [3]. \\ 1 Department of Cardiothoracic Surgery, Damietta Faculty of Medicine, Al-Azhar University, Egypt \\ 2 Department of Pediatric Surgery, Damietta Faculty of Medicine, Al-Azhar University, Egypt \\ ${ }^{3}$ Department of Cardiothoracic Surgery, Faculty of Medicine, Al-Azhar University, Egypt
}

Corresponding author: El-Sayed Ramadan Mohamed Hassan

Email: dr.sayedramadanhassan1@gmail.com

Submission date: December 16, 2020; Acceptance date: August 25, 2021

DOI: 10.21608/IJMA.2021.53956.1225

ABSTRACT

Background: Cardiac surgery became more common. This led to increased redo-surgeries with expected increase of overall complications after the redo. The used approach could affect overall outcome. However, this is not addressed well in literature.

Aim of the work: To examine the overall outcome of patients underwent redo-mitral valve replacement [redo-MVR].

Patients and methods: This study is a retrospective comparative study that was conducted in Cardiothoracic Surgery Department, AlHussein University Hospital in the last three years [from January, 1st, 2017 to the end of December 2019]. Collected data included patient demographics, surgical approach and overall short-term outcome.

Results: The current study included 37 patients; the mean age was $45.19 \pm 9.16$ years. The most common indication for redo was pannus formation [48.6\%], followed by thrombosis [45.9\%]. There was no significant difference between preoperative and postoperative heart rhythm. Redo sternotomy was the commonest, reported in all patients, and femoral bypass done for 3 patients. Trans-atrial approach reported in 24 patients [64.86\%] while Trans-septal approach reported in 13 patients [35.14\%]. No significant difference between preoperative and postoperative echo data [Ejection Friction, left atrial dimension or left ventricle end diastolic dimension]. However, there was significant reduction of left ventricle end-systolic dimension [LVESD], pulmonary artery systolic pressure [PASP] and pressure gradient [PG] cross mitral valve after operation. Reoperation for bleeding was not reported in any cases, while need for new pacemaker reported in 2 patients [5.41\%], new postoperative neurological dysfunction reported in new heart failure or need to dialysis in two patients [5.41\%]. The postoperative arrhythmia was reported in 7 patients [18.9\%] and mortality was occurred in three patients [10.8\%].

Conclusion: The results of the current study showed that, both transseptal and transatrial approaches are comparable and no one is superior to the other.

Keywords: Mitral Valve; Reoperation; Transseptal; Tansatrial; Outcome.

This is an open-access article registered under the Creative Commons, ShareAlike 4.0 International license [CC BY-SA 4.0] [https://creativecommons.org/licenses/by-sa/4.0/legalcode.

Citation: Hassan ERM, Elsayaad IM, Sharaa ME. Retrospective Study of Redo Mitral Valve Surgery in Cardiothoracic Surgery Department Al-Hussein University Hospital. IJMA 2021; 3 [4] October-December: 1784-1791 [DOI: 10.21608/IJMA.2021.53956.1225].

* Main subject and any subcategories have been classified according to the research topic 


\section{INTRODUCTION}

The mitral valve is consisted of several components. It contains two leaflets, tendinous chords and the papillary muscles. In addition, it had an annular attachment located at the junction between the atria and the ventricles [1]. The annulus defines the junctional zone which separates the left atrium from the left ventricle, and attaches to the mitral valve [2]. In a normal valve, the leaflets have fan-shaped threads that extend from the papillary muscles and ends into the leaflets. [3]. Regurgitation of the mitral valve [MR] is even more predominant. Although rheumatic heart disease has decreased, MR is the second most common valve disease in European adults ${ }^{[4]}$. When the probability of a successful repair is high, surgical repair should be performed as much as possible ${ }^{[5]}$.

In general, mitral valve repair had a better prognosis than mitral valve replacement [MVR] when operated at the first place. However, MVR is still required in some patients where mitral valve repair is precisely not possible. On the other hand, many patients will require redo-MVR upon due to many indications that will be noticed during the followup. Many approaches had been advocated to prevent the potential complications of redo-sternotomy such as damage to the previous grafts and hemorrhage. These approaches include right thoracotomy, mini-thoracotomy, and port-access surgery. An alternative promising choice is trans-apical transcatheter MV-in-valve implantation, which propose a more safe approach for patients at risk ${ }^{[6]}$.

The main complications for redo surgery include infective endocarditis, paravalvular leak, prosthetic patient mismatch, valve thrombosis and valve degeneration [Bio prosthesis] [7]. Prosthetic valve thrombosis is considered a rare but critical complication of the valve replacement [8]. Other complications include re-exploration for bleeding, supra-ventricular arrhythmias, permanent pacemaker, endocarditis, hemofiltration and cerebrovascular event ${ }^{[7]}$.

\section{THE AIM OF THE WORK}

The aim of this work is to study the overall outcome of patients underwent redo-mitral valve replacement [redoMVR] at Cardiothoracic Surgery Department Al-Hussein University Hospital in last three years over lighting indication of redo and approach to mitral valve.

\section{PATIENTS AND METHODS}

This study is a retrospective comparative study that was conducted in Cardiothoracic Surgery Department, AlHussein University Hospital in the last three years [from January $1^{\text {st }}, 2017$, to the end of December 2019].

\section{Inclusion criteria}

This retrospective study included all patients who underwent redo-mitral valve replacement with either mechanical or bioprosthetic valves.

\section{Exclusion criteria}

Alternative mitral valve intervention [e.g. mitral valve repair, mitral valvuloplasty, open or closed mitral commissurotomy] without MVR, coronary artery bypass graft [CABG], end stage renal or hepatic diseases.

\section{Methods}

Patients were identified and data was collected from medical records.

\section{The Preoperative assessment included}

- Detailed history.

- Full clinical examination.

- Investigation including: Laboratory work up, chest x ray, electrocardiography [ECG] for heart rhythm and presence of permanent pacemaker, transthoracic echocardiography and trans-esophageal echo for assessment of ejection fraction, other valvular lesions, left atrial size and detection of left atrial thrombus.

- Indications of redo-surgery.

\section{Intraoperative assessment}

Included total operation time, total bypass time, cross clamp time, type of cardioplegia, [femoral bypass with or without], need for a temporary or permanent pacemaker after surgery patients need for the inotropic support or not and other intraoperative complications.

\section{Postoperative assessment included}

- Full intensive care unit [ICU] monitoring.

- Postoperative cardiac rhythm, need for transfusion and incidence of postoperative complications such as myocardial infarction, cerebrovascular accident, renal failure, respiratory failure, sternal infection, pneumonia and early mortality.

- ICU medication including the need for inotropic support.

- Hospital stay. 
- Early postoperative laboratory investigations, electrocardiogram [ECG] and echocardiography before discharge from hospital.

- The favorable outcome was assigned to patients with absent in-hospital mortality and improved clinical signs after surgery, including reductions of preoperative medications. Otherwise, the outcome was assigned as unfavorable.

\section{Statistical analysis of data}

Data were analyzed using statistical package for social sciences [SPSS] version 19 [SPSS Inc, Chicago, USA], running on IBM compatible computer. Independent samples $[t]$ test and chi square tests were used to compare groups. For all tests $p$ value $<0.05$ were considered significant.

\section{RESULTS}

The current work included 37 patients; their age ranged between 27 to 63 years; the mean age was $45.19 \pm 9.16$ years. In addition, 14[37.8\%] patients were males and 23 [62.2\%] were females. Smoking was reported in 13 subjects [35.1\%] and $5[13.51 \%]$ had history of diabetes, while 5 [13.51\%] had history of hypertension. The most common indication was pannus formation [reported in 18 patients; 48.6\%], followed by thrombosis in 17 patients [45.9\%], then paravalvular leak in 2 patients [5.5\%] and prosthetic valve dysfunction not reported in any patients. No patients had grade I "New York Heart Association" [NYHA] class, 2 [5.5\%] were grade II, 18 [48.6\%] were grade III and 17 [45.9\%] were grade IV. The surgical technique was redo-sternotomy among all patients. Three out of them [8.11\%] had femoral bypass. The approach was trans-atrial among 24 patients [64.86\%] and transseptal among 13 [35.14\%].

In the current work, there was no significant difference after redo surgery regarding sinus rhythm, ejection fraction, left atrial $[\mathrm{LA}]$ dimension and left ventricle end diastolic dimension [LVEDD]. However, there was significant decrease of LVESD, PASP and PG gross mitral valve after surgery when compared to corresponding values before surgery [Table 1].

Regarding operative parameters, the bypass time ranged between 88 to 105 minutes. The cross-clamp time [MV replace] ranged between 68 to 80 minutes. The prosthesis size ranged between 27 to 33 , while weaning from bypass was ranged between 27 to 35 minutes. The type of prosthesis was mechanical [100\%] [Table 2].

As regard postoperative assessment, the postoperative Ventilation time it ranged between 0.75 to 4 [days], the mean value was $1.51 \pm 1.00$ days. In addition, ICU stays ranged between 3 to 5 days; the mean value was $3.86 \pm 0.82$ days. The total duration of hospital stay ranged between 7 to 11 days; the mean value was $8.81 \pm 1.43$ days [Table 3].

As regard to postoperative in hospital complications, the reoperation for bleeding not reported in any cases, while need for new pacemaker reported in 2 patients [5.41\%], new postoperative neurological dysfunction, reported in 2 patients [5.41\%], new heart failure or need to dialysis in 3 patients [8.1\%], postoperative arrhythmia was reported in 4 patients [10.81\%] and mortality was occurred in 3 patients [8.10\%] [Table 4].

The outcome was favorable among 20 patients [54.1\%] and unfavorable among 17 [45.9\%]. Favorable outcome, regardless of the approach, was significantly associated with younger age. No significant associations were observed with patient gender, history of pulmonary disease or diabetes, indications of redo surgery and NYHA class. In addition, there were no associations between favorable outcome and ejection fraction, surgical technique, operative data, ICU stay duration, or type of prosthesis. Favorable outcome was linked to high percentage of smoking [Table 5].

Table [1]: Comparison between preoperative and postoperative heart rhythm

\begin{tabular}{|llcccc|}
\multirow{4}{*}{$\begin{array}{l}\text { Heart } \\
\text { rhythm }\end{array}$} & Sinus rhythm & $24[64.9 \%]$ & $20[54.1 \%]$ & -0.946 & 0.173 \\
\cline { 2 - 6 } & Atrial fibrillation/flutter & $11[29.6 \%]$ & $15[40.4 \%]$ & 0.973 & 0.166 \\
\cline { 2 - 6 } Echocardiography & Complete heart block/pacing & $2[5.5 \%]$ & $2[5.5 \%]$ & 0.0 & 0.50 \\
& Ejection Friction [\%] & $50.16 \pm 6.1$ & $53.59 \pm 9.76$ & -1.81 & 0.074 \\
\cline { 2 - 6 } & LA Dimensions [Cm] & $5.23 \pm 0.69$ & $5 \pm 0.58$ & 1.55 & 0.123 \\
\cline { 2 - 6 } & LVED [Cm] & $5.88 \pm 0.32$ & $5.88 \pm 0.32$ & 0.0 & 1.00 \\
& LVES [Cm] & $4.12 \pm 0.31$ & $3.83 \pm 0.23$ & 4.57 & $0.001^{*}$ \\
\cline { 2 - 6 } & PASP [mmHg] & $50.35 \pm 12.38$ & $42.3 \pm 5.3$ & 3.64 & $0.007^{*}$ \\
\cline { 2 - 6 } & PG Cross Mitral valve [mmHg] & $16.03 \pm 3.56$ & $4 \pm 0.82$ & 20.03 & $0.001^{*}$ \\
\hline
\end{tabular}




\begin{tabular}{|c|c|c|c|}
\hline \multirow{2}{*}{\multicolumn{2}{|c|}{ Parameters }} & \multicolumn{2}{|c|}{ Total $[\mathrm{n}=37]$} \\
\hline & & Average [or number] & Mean \pm SD [or $\%$ \\
\hline \multicolumn{2}{|l|}{ Bypass time [min] } & $88-105$ & $92.43 \pm 3.44$ \\
\hline \multicolumn{2}{|c|}{ Cross-clamp time [MV replace] } & $68-80$ & $73.7 \pm 3.66$ \\
\hline \multicolumn{2}{|c|}{ Size of prosthesis } & $27-33$ & $29.92 \pm 2.29$ \\
\hline \multicolumn{2}{|c|}{ Weaning from bypass } & $27-35$ & $30.97 \pm 2.59$ \\
\hline \multirow[t]{2}{*}{ Prosthesis type } & Bioprosthesis & 0 & $0 \%$ \\
\hline & Mechanical & 37 & $100 \%$ \\
\hline \multirow[t]{3}{*}{ Cardiac Supports } & Adrenalin & 37 & $100 \%$ \\
\hline & Nor-Adrenalin & 3 & $8.11 \%$ \\
\hline & Dopamine & 22 & $59.46 \%$ \\
\hline
\end{tabular}

Table [3]: Post-operative assessment data

\begin{tabular}{|c|c|c|}
\hline \multirow[t]{2}{*}{ Parameters } & \multicolumn{2}{|c|}{ Total [n=37] } \\
\hline & Average & Mean \pm SD \\
\hline Ventilation time [in days] & $0.75-4 ;[18-96 \mathrm{H}]$ & $1.51 \pm 1.00$ \\
\hline ICU stay [in days] & $3-5$ & $3.86 \pm 0.82$ \\
\hline Total duration of hospital stay [in days] & $7-11$ & $8.81 \pm 1.43$ \\
\hline
\end{tabular}

Table [4]: Postoperative in hospital complications

\begin{tabular}{|l|c|c|}
\hline \multicolumn{1}{c}{ Variables } & Number & $\%$ \\
\hline Reoperation for bleeding or tamponade & 0 & $0 \%$ \\
\hline Patients requiring new pacemaker & 2 & $5.41 \%$ \\
\hline New post-op neurological dysfunction & 2 & $5.41 \%$ \\
\hline New HF/dialysis postoperatively & 3 & $8.12 \%$ \\
\hline Mortality & 3 & $8.12 \%$ \\
\hline Post-operative arrhythmia & 4 & $10.81 \%$ \\
\hline
\end{tabular}

Table [5]: Association between favorable outcome and studied variables

\begin{tabular}{|c|c|c|c|c|c|}
\hline \multirow{2}{*}{\multicolumn{2}{|c|}{ Age }} & Unfavorable & Favorable & Test & $\mathbf{P}$ \\
\hline & & $52.82 \pm 4.90$ & $48.05 \pm 6.54$ & 2.47 & $0.018^{*}$ \\
\hline \multirow[t]{2}{*}{ Sex } & Male & $4[23.5 \%]$ & $10[50.0 \%]$ & \multirow[t]{2}{*}{2.93} & \multirow[t]{2}{*}{0.09} \\
\hline & Female & $13[76.5 \%]$ & $10[50.0 \%]$ & & \\
\hline \multicolumn{2}{|l|}{ Smoking } & $3[17.6 \%]$ & $10[50.0 \%]$ & 4.22 & $0.040^{*}$ \\
\hline \multicolumn{2}{|c|}{ History of Hypertension } & $3[17.6 \%]$ & $2[10.0 \%]$ & 3.46 & 0.06 \\
\hline \multicolumn{2}{|c|}{ History of Diabetes } & $3[17.6 \%]$ & $2[10.0 \%]$ & 0.03 & 0.85 \\
\hline \multirow{4}{*}{$\begin{array}{l}\text { Redo } \\
\text { indications }\end{array}$} & Thrombosis & $10[58.8 \%]$ & $7[35.0 \%]$ & \multirow[t]{4}{*}{1.43} & \multirow[t]{4}{*}{0.69} \\
\hline & Pannus formation & $10[58.8 \%]$ & $8[40.0 \%]$ & & \\
\hline & Paravalvular leak & $1[5.8 \%]$ & $1[5.0 \%]$ & & \\
\hline & Prosthetic valve dysfunction & $0[0.0 \%]$ & $0[0.0 \%]$ & & \\
\hline \multirow{4}{*}{$\begin{array}{l}\text { NYHA } \\
\text { Class }\end{array}$} & Class-I & $0[0.0 \%]$ & $0[0.0 \%]$ & \multirow[t]{4}{*}{6.33} & \multirow[t]{4}{*}{0.17} \\
\hline & Class-II & $1[5.8 \%]$ & $1[5.0 \%]$ & & \\
\hline & Class-III & $10[58.8 \%]$ & $8[40.0 \%]$ & & \\
\hline & Class-IV & $12[70.5 \%]$ & $5[25.0 \%]$ & & \\
\hline
\end{tabular}

\section{DISCUSSION}

Cardiac surgeries are increased all over the world during the past decades. As a result, more patients with mitral valve redo are reported due to different etiologies. This redo surgery is a challenging practice due to its associated higher risk of morbidity and mortality [9]. Further evaluations of factors associated with its outcome are required. Thus, the current work was designed to check for the outcome of redo mitral valve replacement surgery.

Results regarding patients age and sex are partially in agreement with Castillo-Sang et al. ${ }^{[10]}$ who reported that, females represented $63.8 \%$ of their patients, and the mean [SD] age was 61.3 [13.9] years. The age of our patients is younger, and this is attributed to different inclusion criteria 
and the early heart disease in our patients, due to different factors. In addition, our patients are heterogeneous compared to their patients who had only pulmonary hypertension. Furthermore, Ejiofor et al. [11] reported that, the mean age was $64 \pm 12$ years for redo-mitral valve repair and $63 \pm 15$ years for prior mitral valve replacement, with $60 \%$ being women in both groups.

In the current study, the most common indications were pannus formation [reported in 18 patients; $48.6 \%$ ], followed by thrombosis in 17 patients [45.9\%]. These results are in contradiction to those reported by Castillo-Sang et al. [10] who reported that, prosthesis dysfunction was the most common indication [53.6\%], followed by myxomatous, calcific, and rheumatic disease [both $34.8 \%$ ]. Again, this is due to different inclusion criteria. Sampath Kumar et al. [12] also reported that the most common indications of redoMVR were failed MV repair [38\%] and valve thrombosis [32\%].

Regarding NYHA classification among studied groups, no patients [0\%] were grade I, $2[5.5 \%]$ were grade II and 18 [48.6\%] were grade III and 17 [45.9\%] were grade IV. These results are not in agreement with Onorati et al. [13] who reported that 18 [7.3\%] were grade I, 81 [32.9\%] were grade II and 122 [49.6\%] were grade III and 25 [10.2\%] were grade IV. Current results are also in agreement with Vohra et al. ${ }^{[14]}$ regarding the absence of significant association between NYHA class and outcome. Ejiofor et al. [11] found similar findings and explained it by the preserved left ventricular ejection fraction in their patients [more than $60 \%$ ].

In the current study, there is no significant difference between preoperative and postoperative heart rhythm in studied group; sinus rhythm was reported among 24 [64.9\%], atrial fibrillation/flutter among 11 [29.7\%] and complete heart block/pacing among 2 [5.5\%]. Regarding postoperative heart rhythm, sinus rhythm was reported among 20 [54.1\%], atrial fibrillation/flutter among 15 [40.4\%] and complete heart block/pacing among 2 [5.5\%], one of them need permanent pacemaker. These results are not in agreement with Fukunaga et al. ${ }^{[15]}$ who reported that atrial fibrillation was observed in almost $70 \%$ of patients of study with no significant difference in sinus rhythm and pacing. Masuda et al. ${ }^{[16]}$ found that the majority of patients [96\%] with preoperative sinus rhythm remained as such postoperatively, which was not statistically significant. Rezahosseini et al. [17] results showed that the postoperative atrial fibrillation was still higher than preoperative atrial fibrillation and left atrial size factors.

Regarding surgical technique, redo sternotomy was the most common, reported in 37 patients [100\%], followed by femoral bypass 2 patients [8.11\%]. Regarding the approach, 24 patients [64.86\%] were operated through Trans- atrial and 13 [35.14\%] through transseptal and there was no significant difference between both approaches, while no patient reported redo via thoracotomy. Patel et al. [18] concluded that reoperation of mitral valve surgery via thoracotomy is safe and is associated with lesser ventilation time, reduced ICU and total hospital stay, rapid recovery following surgery, and decreased need for perioperative blood transfusion. Other studies $[19,20]$ support these results, particularly in the setting of primary mitral valve procedures. The trans-atrial approach may reduce left ventricular apical function, but it is not permanent [21]. For patients with reduced left ventricular ejection fraction or functional mitral regurgitation, this may not be the best approach. In the case of a pre-existing artificial heart valve in the aortic location, this can also be a technical challenge [22], whereas the TS approach may be less challenging, although only limited data are available ${ }^{[23] .}$

Regarding operative parameters, the bypass time ranged between 88 to 105 minutes. The cross-clamp time ranged between 68 to 80 minutes. While Onorati et al. [13] reported that cross-clamping time $87 \pm 37 \mathrm{~min}$ and bypass time $133 \pm 56 \mathrm{~min}$. The type of prosthesis was Bioprosthesis [100\%]. The results agree with Kaneko et al. [24] who showed the superiority of mechanical valves, especially in younger populations, and reported higher use of such mechanical prosthesis in their patients, as in the current work. While Onorati et al. ${ }^{[13]}$ reported that crossclamping time $87 \pm 37 \mathrm{~min}$ and bypass time $133 \pm 56 \mathrm{~min}$.

Regarding postoperative complications, the reoperation for bleeding not reported in any cases, while need for new pacemaker reported in 2 patients [5.41\%], new postoperative neurological dysfunction reported in 2 patients [5.41\%]., postoperative arrhythmia was reported in 4 patients [10.81\%] and mortality was occurred in 3 patients $[8.10 \%]$ that's was due to difficulty weaning, low cardiac output in spite of supports and finally renal impairment. While Fukunaga et al. ${ }^{[15]}$ who reported that patients with renal dysfunction need dialysis were found in $152[36.7 \%]$ patients. The number of patients who required hemodialysis was 6 [1.4\%]. Onorati et al. [13] reported mortality in 3 patients [6.5\%], reoperation for bleeding or tamponade 6 [13.0\%] and Need for permanent pacemaker in $2[4.3 \%]$ which in partially agreement with this study.

Favorable outcome was significantly associated with younger age. However, no significant association was observed with patient gender, history of hypertension or diabetes, indications of redo surgery and NYHA class. In addition, no association was reported between favorable 
outcome and surgical technique, operative data, ICU stay duration, or type of prosthesis. Unexpectedly, favorable outcome was linked to high percentage of smoking. However, it could be attributed to the fact that, smoking is restricted to males.

On the other side, Sampath Kumar et al. [12] reported that the overall mortality rate of reoperation for heart valve disease is higher than that of the initial operation. Their observations showed that the factors leading to higher mortality were active infective endocarditis, a higher grade of preoperative NYHA, and valve thrombosis. These results are in controversy to the current work and could be attributed to different inclusion criteria.

Left ventricular outflow tract [LVOT] obstruction may occur after redo surgical mitral valve replacement [SMVR] due to interference by the surgical implant [25]. Guerrero et al. ${ }^{[26]}$ reported that LVOT obstruction was reported in $5.4 \%$ patients, and more than mild mitral regurgitation was reported in $4.3 \%$. In-hospital mortality was $6.9 \%$ and 30 day mortality was $9 \%$.

The transatrial [TA] approach allows direct access to the mitral valve position, an anatomically short distance and easy to operate, which is attributed to the initial success of this approach, which improves operator familiarity. In fact, with this method, most mitral valve operations can be performed by the surgeon standing on the right or left side of the patient [27]. It is important that the type of mitral valve surgery each patient receives and / or their ability to perform the accompanying labyrinth surgery is not affected by the decision to perform a non-sternotomy [28].

The incidence of one-month postoperative mortality in the current work was $10.8 \%$. This is in line with CastilloSang et al. [10] who reported an incidence of $10.1 \%$ after redo-mitral valve surgery in patients with pulmonary hypertension. In addition, they reported that, postoperative arrhythmia was the most common complications [45.3\%] which in line with the current work, despite the difference in percentage of occurrence [18.9\% in the current work]. Previous reports suggest that re-MVR is a high-risk procedure with a $5 \%$ to $12 \%$ operative mortality ${ }^{[14,29]}$ and a 7 -year survival of $69 \%$ [30]. This is largely due to the increased technical difficulty inherent in reoperation, the more fragile patients undergoing reoperation, and prosthetic valve endocarditis is a common indication for reoperation [11].

Akay et al. ${ }^{[31]}$ reported a reoperative mortality of $6.4 \%$ in cohort of 62 patients, and Vohra et al. [14] reported a $12 \%$ rate in a cohort of 49 patients over a 10-year experience.
Fukunaga et al. ${ }^{[15]}$ reported that, the overall rate of hospital death was 5.8\% [32/555 redo procedures] and the 30-day mortality was $3.0 \%$ [17/555 redo procedures]. Nienaber and Glower ${ }^{[32]}$ compared the mini-transseptal [TS] and the transatrial approaches and found no increase in the incidence of postoperative atrial fibrillation in the former technique. Perhaps the differences between our results and those reported by the Nienaber and Glower ${ }^{[32]}$ study are due to the shorter atrial incision, faster atrial closure time, and lesser injury to the sinus nodal artery in the miniTS approach. Wang et al. [33] concluded that the extending vertical transseptal approach affords excellent exposure of the mitral valve.

The present study had some limitations; data are lacking regarding the type of valves used in the first operation, and the duration before redo surgery.

\section{CONCLUSION}

In conclusion, the results of the current study showed that younger patient had good outcome, pannus formation and thrombosis are the most common indication of redo mitral valve replacement, choice of approach is directly in relation without come either intra/or post-operative assessment.

\section{Financial and Non-financial Relationships and Activities of Interest}

None

\section{REFERENCES}

1. Sanchez Vaca F, Bordoni B. Anatomy, Thorax, Mitral Valve. 2021 Jul 31. In: StatPearls [Internet]. Treasure Island (FL): StatPearls Publishing; 2021 Jan-. PMID: 31751074.

2. Lancellotti $P$, Tribouilloy $C$, Hagendorff $A$, Popescu BA, Edvardsen T, Pierard LA, et al. Recommendations for the echocardiographic assessment of native valvular regurgitation: an executive summary from the European Association of Cardiovascular Imaging. Eur Heart J Cardiovasc Imaging. 2013 Jul;14[7]:611-44. DOI: 10.1093/ehjciljet105.

3. Tsang W. Recent advances in understanding and managing mitral valve disease. F1000Res. 2019 Sep 24;8: F1000 Faculty Rev-1686. DOI: 10.12688/ f1000research.16066.1.

4. Zhao D, Zhang B. Are valve repairs associated with better outcomes than replacements in patients with 
native active valve endocarditis? Interact Cardiovasc Thorac Surg. 2014 Dec;19[6]:1036-9. DOI: 10.1093/ icvts/ivu296.

5. Botta L, Cannata A, Bruschi G, Fratto P, Taglieri C, Russo CF, Martinelli L. Minimally invasive approach for redo mitral valve surgery. J Thorac Dis. 2013 Nov;5 Suppl 6[Suppl 6]: S686-93. DOI: 10.3978/ j.issn.20721439.2013.10.12.

6. Sengupta A, Yazdchi F, Alexis SL, Percy E, Premkumar A, Hirji S, et al. Reoperative Mitral Surgery Versus Transcatheter Mitral Valve Replacement: A Systematic Review. J Am Heart Assoc. 2021 Mar 16;10[6]: e019854. DOI: 10.1161/JAHA.120.019854.

7. Chen J, Wang H, Xie X, Dai H, Zhou M, Zheng Y, Zhao L. Long-term left atrial thrombi after mitral valve replacement. J Thromb Thrombolysis. 2021 Jan;51[1]:129-135. DOI: 10.1007/s11239-020-02187-4.

8. Werner N, Kilkowski C, Sutor D, Weisse U, Schneider S, Zahn R. Transcatheter Mitral Valve Implantation [TMVI] Using Edwards SAPIEN 3 Prostheses in Patients at Very High or Prohibitive Surgical Risk: A Single-Center Experience. J Interv Cardiol. 2020 Jan 6; 2020:9485247. DOI: 10.1155/2020/9485247.

9. Zhang H, Xu HS, Wen B, Zhao WZ, Liu C. Minimally invasive beating heart technique for mitral valve surgery in patients with previous sternotomy and giant left ventricle. J Cardiothorac Surg. 2020 Jun 3;15[1]:122. DOI: 10.1186/s13019-020-01171-6.

10. Castillo-Sang M, Guthrie TJ, Moon MR, Lawton JS, Maniar HS, Damiano RJ Jr, Silvestry SC. Outcomes of repeat mitral valve surgery in patients with pulmonary hypertension. Innovations [Phila]. 2015 Mar-Apr; 10 [2]:120-4. DOI: $10.1097 / / \mathrm{MI} .0000000000000139$.

11. Ejiofor JI, Hirji SA, Ramirez-Del Val F, Norman AV, McGurk S, Aranki SF, Shekar PS, Kaneko T. Outcomes of repeat mitral valve replacement in patients with prior mitral surgery: A benchmark for transcatheter approaches. J Thorac Cardiovasc Surg. 2018 Aug;156[2]:619-627.e1. DOI: 10.1016/j.jtcvs. 2018.03.126.

12. Sampath Kumar A, Dhareshwar J, Airan B, Bhan A, Sharma $R$, Venugopal $P$. Redo mitral valve surgery-a long-term experience. J Card Surg. 2004;19[4]:303-7. DOI: 10.1111/j.0886-0440.2004.4054_11.x.

13. Onorati F, Gatti G, Perrotti A, Mariscalco G, Reichart
$D$, Milano $A$, et al. Impact of failed mitral valve repair on hospital outcome of redo mitral valve procedures. Eur $\mathrm{J}$ Cardiothorac Surg. 2017 May 1;51[5]:906-912. DOI: 10.1093/ejcts/ezw436.

14. Vohra HA, Whistance RN, Roubelakis A, Burton A, Barlow CW, Tsang GM, Livesey SA, Ohri SK. Outcome after redo-mitral valve replacement in adult patients: a 10-year single-centre experience. Interact Cardiovasc Thorac Surg. 2012;14[5]:575-9. DOI: 10.1093/icvts/ ivs005.

15. Fukunaga N, Sakata R, Koyama T. Short- and longterm outcomes following redo valvular surgery. J Card Surg. 2018; 33 (2):56-63. DOI: 10.1111/jocs.13534.

16. Masuda $M$, Tominaga $R$, Kawachi $Y$, Fukumura $F$, Morita S, Imoto Y, Toshima Y, Tomita Y, Yasui H. Postoperative cardiac rhythms with superior-septal approach and lateral approach to the mitral valve. Ann Thorac Surg. 1996; 62[4]:1118-22. DOI: 10.1016/00034975[96]00379-7.

17. Rezahosseini O, Rezaei M, Ahmadi Tafti SH, Jalali A, Bina P, Ghiasi A, et al. Transseptal Approach versus Left Atrial Approach to Mitral Valve: A Propensity Score Matching Study. J Tehran Heart Cent. 2015 Oct 27; 10[4]:188-93. PMID: 26985207.

18. Patel NC, Hemli JM, Seetharam K, Graver LM, Brinster DR, Pirelli L, Scheinerman SJ, Hartman AR. Reoperative mitral valve surgery via sternotomy or right thoracotomy: A propensity-matched analysis. J Card Surg. 2019; 34[10]:976-982. DOI: 10.1111/jocs. 14170.

19. Ryan WH, Brinkman WT, Dewey TM, Mack MJ, Prince SL, Herbert MA. Mitral valve surgery: comparison of outcomes in matched sternotomy and port access groups. J Heart Valve Dis. 2010 Jan; 19[1]:51-8; discussion 59. PMID: 20329490.

20. Grant SW, Hickey GL, Modi P, Hunter S, Akowuah E, Zacharias J. Propensity-matched analysis of minimally invasive approach versus sternotomy for mitral valve surgery. Heart. 2019 May;105[10]:783-789. DOI: 10.1136/heartjnl-2018-314049.

21. Barbash IM, Dvir D, Ben-Dor I, Corso PJ, Goldstein SA, Wang Z, et al. Impact of transapical aortic valve replacement on apical wall motion. J Am Soc Echocardiogr. 2013; 26:255-260. DOI: 10.1016/j.echo. 2012.11.003.

22. Wilbring M, Alexiou K, Tugtekin SM, Arzt S, Ibrahim K, 
Matschke K, Kappert U. Pushing the limits - further evolutions of transcatheter valve procedures in the mitral position, including valve-in-valve, valve-in-ring, and valve-in native- ring. J Thorac Cardiovasc Surg. 2014; 147:210-219. DOI:10.1016/ j. jtcvs.2013.09.021.

23. Dvir D [2016]: Transseptal instead of transapical valve implantation: making mitral great again? JACC Cardiovasc Interv. 2016; 9:1175-1177. DOI:10.1016/ j.jcin.2016.04.006.

24. Kaneko T, Aranki S, Javed Q, McGurk S, Shekar P, Davidson M, Cohn L. Mechanical versus bioprosthetic mitral valve replacement in patients $<65$ years old. J Thorac Cardiovasc Surg. 2014 Jan;147[1]:117-26. [DOI: 10.1016/j.jtcvs.2013.08.028].

25. Said SM, Pislaru S, Kotkar KD, Rihal CS, Mauermann WJ, Schaff HV, Dearani JA. Left Ventricular Outflow Tract Obstruction After Transcatheter Mitral Valve-inRing Implantation: A Word of Caution. Ann Thorac Surg. 2016 Dec;102[6]:e495-e497. DOI: 10.1016/ j.athoracsur.2016.03.039.

26. Guerrero M, Dvir D, Himbert D, Urena M, Eleid M, Wang DD, et al. Transcatheter mitral valve replacement in native mitral valve disease with severe mitral annular calcification: results from the first multicenter global registry. JACC Cardiovasc Interv. 2016 Jul 11;9[13]:1361-71. DOI: 10.1016/j.jcin.2016.04.022.

27. Cheung A, Webb JG, Wong DR, Ye J, Masson JB, Carere RG, Lichtenstein SV. Transapical transcatheter mitral valve-in-valve implantation in a human. Ann Thorac Surg. 2009 Mar;87[3]: e18-20. DOI: 10.1016/j.athoracsur.2008.10.016.
28. Seeburger J, Borger MA, Doll N, Walther T, Passage J, Falk V, Mohr FW. Comparison of outcomes of minimally invasive mitral valve surgery for posterior, anterior and bileaflet prolapse. Eur $\mathrm{J}$ Cardiothorac Surg. 2009; 36[3]:532-8. DOI: 10.1016/j.ejcts.2009.03. 058.

29. Potter DD, Sundt TM 3rd, Zehr KJ, Dearani JA, Daly $\mathrm{RC}$, Mullany $\mathrm{CJ}$, et al. Risk of repeat mitral valve replacement for failed mitral valve prostheses. Ann Thorac Surg. 2004; 78[1]:67-72. DOI: 10.1016/j. athoracsur.2004.02.014.

30. Zegdi R, Sleilaty G, Latrémouille C, Berrebi A, Carpentier A, Deloche A, Fabiani JN. Reoperation for failure of mitral valve repair in degenerative disease: a single-center experience. Ann Thorac Surg. 2008; 86[5]:1480-4. DOI: 10.1016/j.athoracsur.2008.07.020.

31. Akay TH, Gultekin B, Ozkan S, Aslim E, Uguz E, Sezgin A, Aslamaci S. Mitral valve replacements in redo patients with previous mitral valve procedures: mid-term results and risk factors for survival. J Card Surg. 2008 Sep-Oct; 23[5]:415-21. DOI: 10.1111/ j.1540-8191.2008.00630.x.

32. Nienaber JJ, Glower DD. Minitransseptal versus left atrial approach to the mitral valve: a comparison of outcomes. Ann Thorac Surg 2006; 82:834-839. DOI: 10.1016/j.athoracsur.2006.04.014.

33. Wang, Wu X, Wei W, Xiang M. Extended Vertical Transseptal Approach versus Transseptal Approach for Mitral Valve Operation. The Heart Surgery Forum 2014; 17[3], E123-E126. DOI. 10.1532/ HSF98. 2014317. 


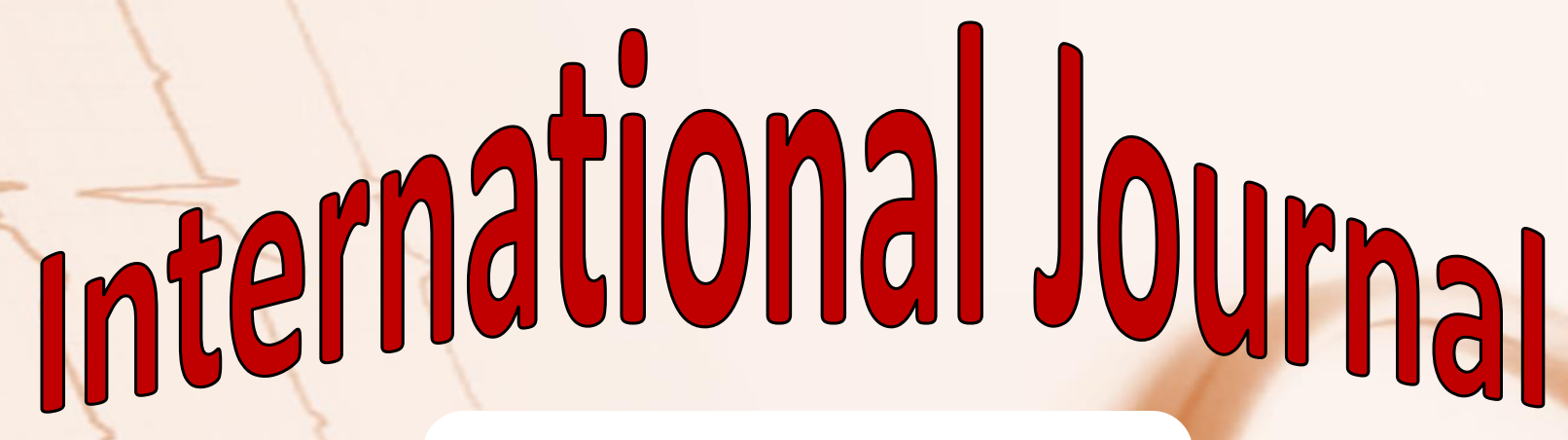

https://ijma.journals.ekb.eg/ Print ISSN: 2636-4174 Online ISSN: 2682-3780

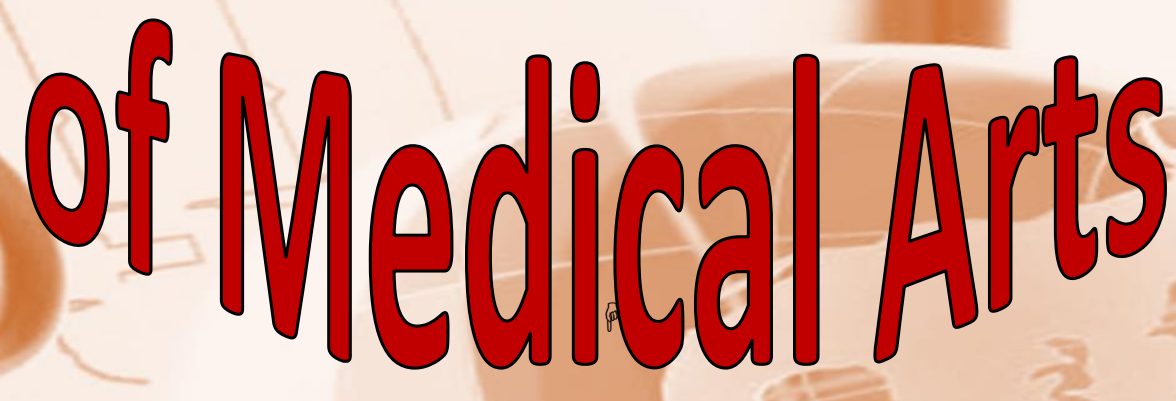

